\title{
Solid strain based finite element implemented in ABAQUS for static and dynamic plate analysis
}

\author{
Derradji Lazhar $^{a^{*}}$, Maalem Toufik ${ }^{a}$, Merzouki Tarek ${ }^{b}$ and Messai Abderraouf ${ }^{\mathfrak{c}}$ \\ ${ }^{a}$ Civil Engineering Department, University of Batna2, Algeria \\ ${ }^{b}$ Laboratoire d'Ingénierie des Systèmes de Versailles, France \\ ${ }^{c}$ Civil Engineering Department, Universityof Sétifl, Algeria

A R T I C L E I N F O $\quad$ A B S T R A C T \\ Article history: \\ Received 10 September 2020 \\ Accepted 5 May 2021 \\ Available online \\ 9 May 2021 \\ Keywords: \\ Strain approach \\ Plate bending \\ Implementation \\ SBH8 \\ ABAQUS

\begin{abstract}
An existing robust three dimensional finite element based on the strain approach is presented. This element is implemented, for the first time in the commercial computer code ABAQUS, by using the subroutine (UEL), for the static and dynamic analysis of isotropic plates, whatever thin or thick. It is Baptised SBH8 (Strain Based Hexahedral with 8 nodes) and has the advantage to overcome the problems involved in numerical locking, when the thickness of the plate tends towards the smallest values. The implementation is justified by the capacities broader than offers this code, especially, in the free frequencies computation. The results obtained by the present element are better than those given by elements used by ABAQUS code and the other elements found in the literature, having the same number of nodes.
\end{abstract}

(C) 2021 Growing Science Ltd. All rights reserved.

\section{Introduction}

Plates are structures widely used in many technological applications. A very large number of finite elements of plate bending problems have been developed. The strain approach has been employed as an alternative to formulate robust plate elements (Abderrahmani et al., 2018; Belarbi \& Charif, 1999; Belounar \& Guenfoud, 2005; Belounar \& Guerraiche, 2014; Guerraiche et al., 2018; Belounar et al., 2018) to increase the accuracy and stability of the numerical solutions as well as to eliminate shear locking phenomena. The use of the strain approach (Belarbi \& Maalem, 2005; Maalem, 2011; Djoudi \& Bahai 2004a,b; Rebiai \& Belounar 2013) has several advantages where it enables to obtain efficient elements with high-order polynomial terms for the displacement functions without the need of including internal nodes. In this paper a hexaedral finite element based on the strain approach with eight nodes, each node possess the three essential external degrees of freedom ( $\mathrm{U}, \mathrm{V}$ and $\mathrm{W})$, is implemented, for the first time, in the ABAQUS computer code by using the UEL subroutine and validated through a series of static and free vibration tests.

The geometry of the SBH8 element (Belarbi \& Charif 1999) and the corresponding kinematic variables are shown in Fig. 1. In every node (i) is attributed the three degree of freedom (d.o.f) "Ui, $\mathrm{Vi}$ and Wi".

\footnotetext{
* Corresponding author.

E-mail addresses: 1.derradji@univ-batna2.dz (D. Lazhar)

(C) 2021 Growing Science Ltd. All rights reserved.

doi: $10.5267 /$ j.esm.2021.5.001
} 


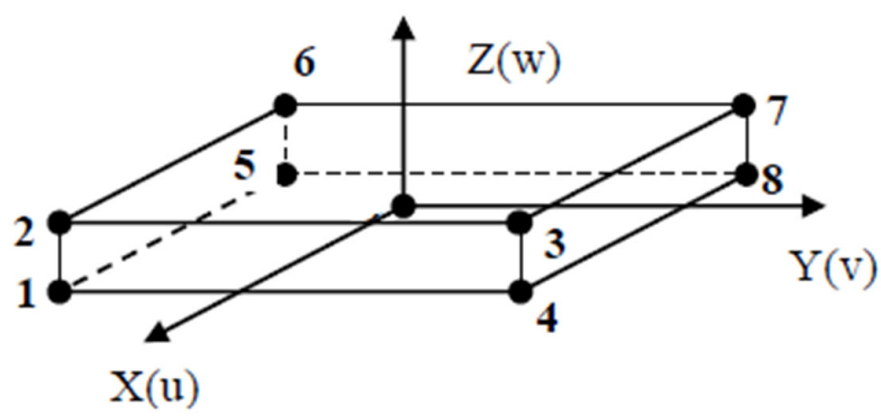

Fig. 1. Geometry of the SBH8 element.

\section{Theoretical considerations}

\subsection{Displacement field}

There are six strain-displacement relations occurring in completely 3D analysis.

$$
\begin{aligned}
& \varepsilon_{x x}=U_{x} \\
& \varepsilon_{y y}=V_{y} \\
& \varepsilon_{z z}=W_{z} \\
& \gamma_{x y}=U_{y}+V_{x} \\
& \gamma_{y z}=V_{z}+W_{y} \\
& \gamma_{x z}=W_{x}+U_{z}
\end{aligned}
$$

where $U, V$ and $W$ : are the displacements in the three directions $\mathrm{X}, \mathrm{Y}$ and $\mathrm{Z}$ respectively. Eq. (2) represents the condition of the rigid body motion (R.B.M). We have:

$$
\begin{aligned}
& \varepsilon_{i j}=0 \\
& \gamma_{i j}=0
\end{aligned}
$$

The integration of Eq. (2) allows obtaining a particular solution:

$$
\begin{aligned}
& U_{R}=a_{1}+a_{4} y+a_{6} z \\
& V_{R}=a_{2}-a_{4} x-a_{5} z \\
& W_{R}=a_{3}+a_{5} y-a_{6} x
\end{aligned}
$$

where Eq. (3) represent the displacement fields corresponding to the rigid body motion (R.B.M). The present element is an eight hexahedral node with three degrees of freedom (d.o.f) by node (Fig. 1). Therefore, the displacement field has to contain twenty-four independent constants. Six of them (a1, a2 , ..., a6) are already used to represent the R.B.M, it remains so eighteen $(a 7, a 8, \ldots$, a24) to represent in a rough way strain in the element, while verifying the six equations of compatibility. The strain field is:

$$
\begin{aligned}
& \varepsilon_{\mathrm{xx}}=\mathrm{a}_{7}+\mathrm{a}_{8} \mathrm{y}+\mathrm{a}_{9} \mathrm{z}+\mathrm{a}_{10} \mathrm{yz} \\
& \varepsilon_{\mathrm{yy}}=\mathrm{a}_{11}+\mathrm{a}_{12} \mathrm{x}+\mathrm{a}_{13} \mathrm{z}+\mathrm{a}_{14} \mathrm{xz} \\
& \varepsilon_{\mathrm{zz}}=\mathrm{a}_{15}+\mathrm{a}_{16} \mathrm{x}+\mathrm{a}_{17} \mathrm{y}+\mathrm{a}_{18} \mathrm{xy} \\
& \gamma_{\mathrm{yz}}=\mathrm{a}_{19}+\mathrm{a}_{20} \mathrm{x} \\
& \gamma_{\mathrm{xz}}=\mathrm{a}_{21}+\mathrm{a}_{22} \mathrm{y} \\
& \gamma_{\mathrm{xy}}=\mathrm{a}_{23}+\mathrm{a}_{24} \mathrm{z}
\end{aligned}
$$


Substituting equations Eq. (4) into Eq. (1) and solving the resulting differential equations and adding to them (i.e. Eq. 3) gives:

$$
\begin{gathered}
U=a_{1}+a_{4} y+a_{6} z+a_{7} x+a_{8} x y+a_{9} x z+a_{10} x y z-0.5 a_{12} y^{2}-0.5 a_{14} y^{2} z- \\
0.5 a_{14} z^{2}-0.5 a_{18} y z^{2}+0.5 a_{21} z+0.5 a_{23} y+a_{24} \mathrm{yz} \\
\begin{array}{c}
V=a_{2}-a_{4} x-a_{5} z+a_{11} y+a_{12} x y+a_{13} y z+a_{14} x y z-0.5 a_{8} x^{2}-0.5 a_{10} x^{2} z \\
-0.5 a_{17} z^{2}-0.5 a_{18} x z^{2}+0.5 a_{19} z+0.5 a_{23} x+a_{20} x z
\end{array} \\
\begin{array}{c}
W=a_{3}+a_{5} y-a_{6} x+a_{15} z+a_{16} x z+a_{17} y z+a_{18} x y z-0.5 a_{9} x^{2}-0.5 a_{10} x^{2} y \\
-0.5 a_{13} y^{2}-0.5 a_{14} x y^{2}+0.5 a_{19} y+0.5 a_{21} x+a_{22} x y
\end{array}
\end{gathered}
$$

In matrix form, we can write:

$$
\{u\}=\left[C_{u}\right]\{a\}
$$

$\{u\}$ is the displacement vector, $\left[C_{u}\right]$ is the matrix of variables $\mathrm{x}, \mathrm{y}$ and $\mathrm{z} .\{a\}$ is the constants vector.

By replacing in Eq. (6) with the nodal coordinates, wehave $\left\{q_{e}\right\}=[A]\{a\}$

$\left\{q_{e}\right\}$ is the element nodal displacements vector, $[A]$ is the element matrix of the nodal coordinates.

\subsection{Global equilibrium equation for static and free vibration}

The following Equations can be written:

$$
\begin{aligned}
& {[K]\{q\}=\{F\}} \\
& {[K]\{q\}-\omega^{2}[M]\{q\}=\{0\}}
\end{aligned}
$$

$\{q\}$ is the structural global d.o.f vector, $[K]$ is the stiffness matrix

$[M]$ is the mass matrix, and $\{F\}$ is the load vector

$\boldsymbol{\omega}$ : is the natural frequency.

\subsubsection{Evaluation of the element stiffness matrix $\left[\boldsymbol{K}_{\boldsymbol{e}}\right]$}

The evaluation of the element stiffness matrix is summarized with the evaluation of the following expression:

$$
\left[K_{e}\right]=\left[A^{-1}\right]^{T}\left[K_{0}\right]\left[A^{-1}\right]
$$

where

$$
\left[K_{0}\right]=\iiint_{V}[Q]^{T}[D][Q] d x d y d z
$$

and

$$
[B]=[Q]\left[A^{-1}\right]
$$

The classic strain matrix is [B], the matrix [A] and its inverse can be estimated numerically; one realizes that the evaluation of the integral (10) becomes the key of the problem. The element shape is regular, numerical integration is reduced to an analytical integration.

\subsubsection{Evaluation of the element mass matrix $\left[\boldsymbol{M}_{\boldsymbol{e}}\right]$}

$$
\left[M_{e}\right]=\rho\left(\iiint_{V}[N]^{T}[N] d x d y d z\right)
$$


where the interpolation matrix is

$$
[N]=[C u][A]^{-1}
$$

\subsection{Mechanical characteristics of the material}

The behavior law is modified by the introduction of the plane stress constants and a corrective coefficient of transverse are noted $K$. This method, which is underlying in Ahmad's element (Ahmad et al., 1970), consists in modifying the matrix of elastic constants, so as to represent with more meadows the real behavior of plates and shells that are thin or thick. The matrix in Eq. (14) is a modified form (fictitious material) of the material matrix properties:

$$
[D]=D_{1}\left[\begin{array}{cccccr}
1 & v & 0 & 0 & 0 & 0 \\
& 1 & 0 & 0 & 0 & 0 \\
& & D_{2} & 0 & 0 & 0 \\
& & & D_{3} & 0 & 0 \\
& & & & K D_{3} & 0 \\
& & & & & K D_{3}
\end{array}\right]
$$

where

$$
D_{1}=\frac{E}{\left(1-v^{2}\right)} ; \quad D_{2}=\frac{(1-v)^{2}}{(1-2 v)} ; D_{3}=\frac{(1-v)}{2}
$$

$\mathrm{E}$ is the modulus of elasticity; $v$ is the Poisson's ratio

$\mathrm{K}=\pi^{2} / 12$ inUflyand-Hencky-Mindlin's theory

$\mathrm{K}=5 / 6$ in Reissner's theory

\section{Numerical investigations}

The finite element calculations are carried out using different elements:

ABAQUS elements:

- C3D8: a classical eight-node first-order hexahedral element with an exact numerical integration scheme.

- C3D8I:a fully integrated eight-node hexahedral element with 13 incompatible modes used to prevent the transverse shear and Poisson's ratio locking

○ C3D20: a classical 20-node second-order hexahedral element with an exact numerical integration scheme.

SBBNN: Strain based brick element with nine nodes (Messai et al.; 2019)

SFR8:an eight-node hexahedral element based on the concept of the space fiber rotation (Ayad et al., 2013)

\subsection{Static analysis}

\subsubsection{Cantilever beam under in-plane bending load}

In this test, a console beam under a pure bending moment $\mathrm{M}=2000$ is analyzed in order to assess the sensitivity to the distorted mesh. The beam shown in the following figure (Fig. 2) is divided into two brick elements with an eccentricity $e \in[0,4.9]$ as suggested by Piltner \& Taylor (1995). The shape of the two elements varies depending on the variety of the distortion parameter e. if $\mathrm{e}=0$, the two elements are rectangular. But with the increase in e, the mesh will be more distorted. The vertical displacement normalized at point $\mathrm{A}$ is determined by the ratio of the calculated displacement to the reference displacement. The vertical displacement of reference at the free end is equal to 100. Normalized vertical displacement at the free end of the beam is shown in Fig. 3. It can be seen that the present element is less 
sensitive to mesh distortion than other elements and becomes more accurate than the solid elements of ABAQUS (eight and twenty nodes) for severe distortion.

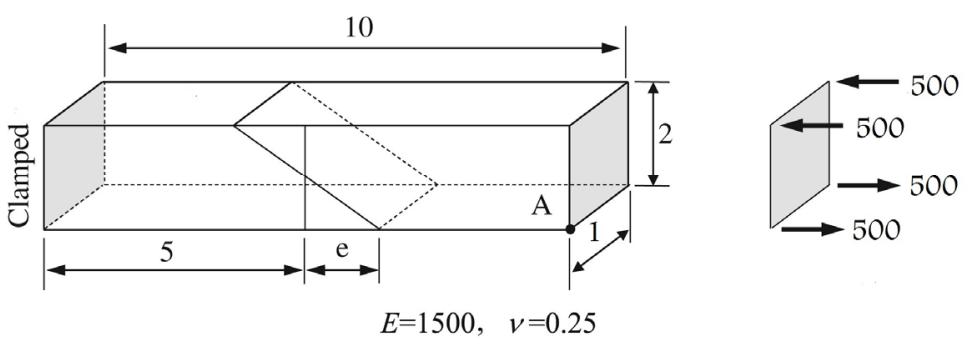

Fig. 2. Cantilever beam modeled by two distorted elements.

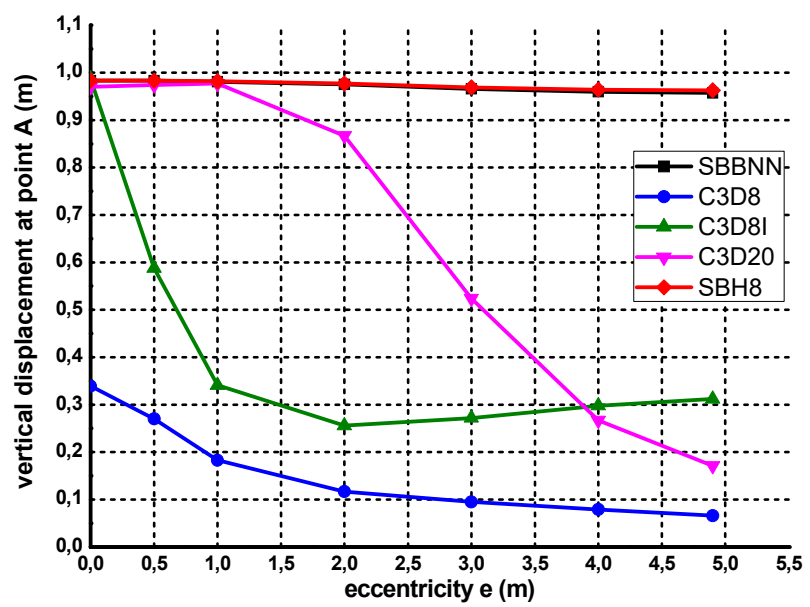

Fig. 3. Normalized vertical displacement at the free end of the beam.

\subsubsection{Simply supported square plate subjected to a central concentrated load}

A simply supported square plate subjected to a concentrated load at the center is analyzed (Fig. 4). The example is studied by (Andelfinger \& Ramm, 1993; Areias et al., 2003; De Sousa et al., 2003; Ayad et al., 2013). Due to the symmetry of the problem, only the quarter of the plate is modeled using a regular mesh. The transverse reference displacement at the center is calculated by Kirchhoff's theory and equal to the unit. The obtained results are presented in Table 1.

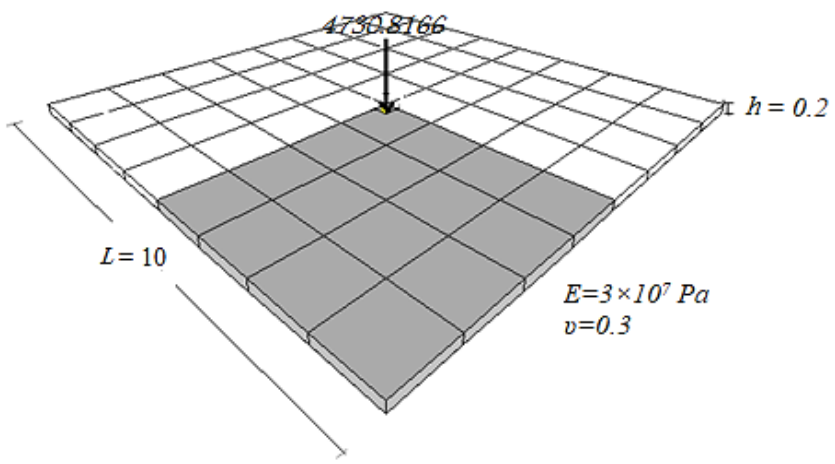

Fig. 4. Simply supported square plate. 
Table 1. Normalized transverse displacement of the center of the plate (Simply supported square plate).

\begin{tabular}{llllll}
\hline $\mathbf{N}$ & SBBNN & SFR8 & C3D8I & C3D20 & SBH8 \\
\hline \multirow{2}{*}{} & 0.753 & 0.266 & 0.399 & 0.868 & $\mathbf{0 . 7 5 3}$ \\
& $(66)^{*}$ & $(108)$ & $(106)$ & $(153)$ & $\mathbf{( 5 4 )}$ \\
$\mathbf{4}$ & 0.929 & 0.423 & 0.908 & 0.978 & $\mathbf{0 . 9 2 9}$ \\
& $(198)$ & $(300)$ & $(358)$ & $(465)$ & $\mathbf{( 1 5 0 )}$ \\
$\mathbf{8}$ & 0.989 & 0.558 & 0.999 & 1.007 & $\mathbf{0 . 9 8 9}$ \\
& $(678)$ & $(972)$ & $(1318)$ & $(1593)$ & $\mathbf{( 4 8 6 )}$ \\
$\mathbf{1 6}$ & 1.009 & 0.707 & 1.012 & 1.017 & $\mathbf{1 . 0 0 9}$ \\
& $(2502)$ & $(3468)$ & $(5062)$ & $(5865)$ & $\mathbf{( 1 7 3 4 )}$ \\
\hline
\end{tabular}

* : Number of d.o.f

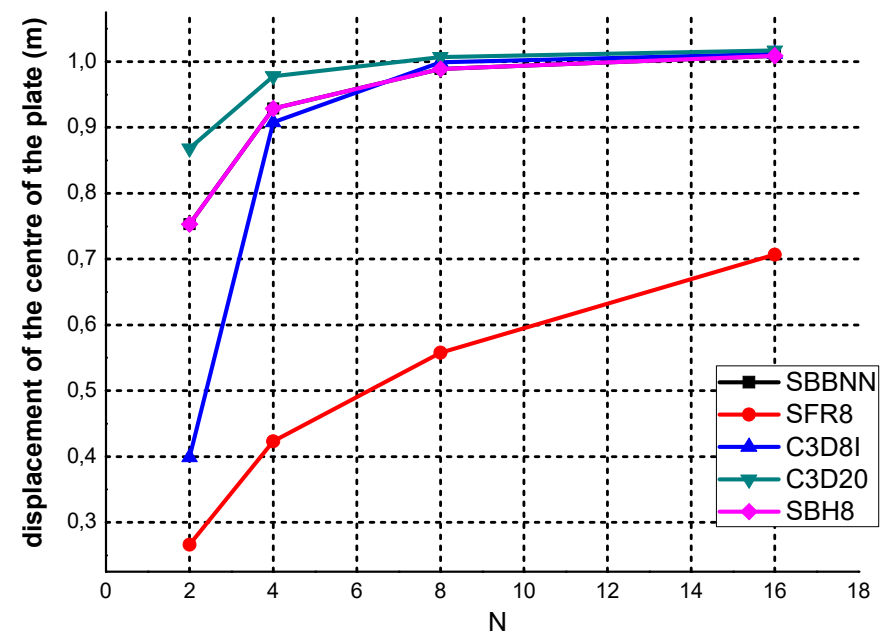

Fig. 5. Normalized transverse displacement of the center of the plate (simply supported square plate).

The SBH8, which has the littlest number of d.o.f. gives the best result for 16 elements mesh, as well as the SBBNN as shown in Fig. 5. We can say that the SBH8, relatively to its configuration (number of nodes and number of d.o.f) gives the best results.

\subsubsection{Convergence tests for circular plates}

In this test, we evaluate the performance of the present element in shear locking. A circular plate subjected to a central concentrated load is considered. The thickness of the plate is $t=0.1 \mathrm{~m}$. The Young's modulus of the plate is $E=10.92 \mathrm{GPa}$, the Poisson ratio is $v=0.3$, the radius is $R=5 \mathrm{~m}$. Two types of boundary conditions are applied, simply supported and clamped edges. Kirchhoff's theory calculates the transverse reference displacement at the center. Due to the symmetry, only a quarter of the circular plate is modeled with 12, 48, 108 and 192 elements as shown in (Fig. 6).

Figs. 7 and 8, show the transverse displacement values for the center of disc for simply support and clamped boundary conditions, respectively. It is seen that the SBH8 gives almost the same results as the SBBNN, and converges faster than the other elements. 

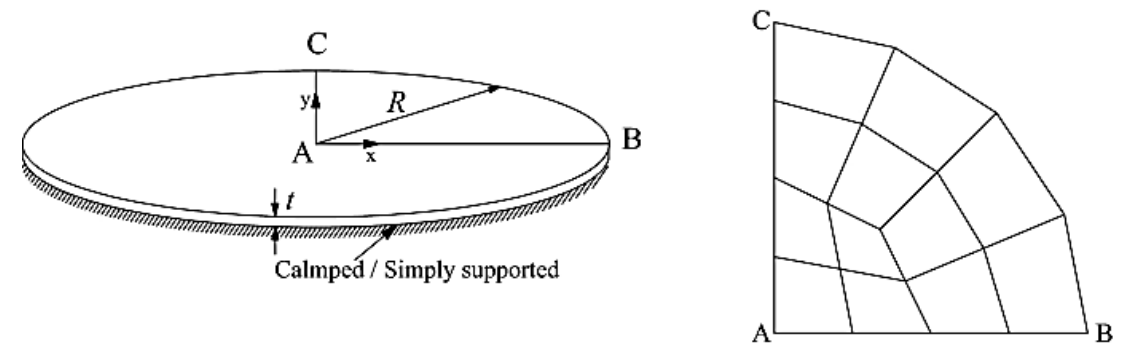

Fig. 6. The circular plate modeled with 12 elements.

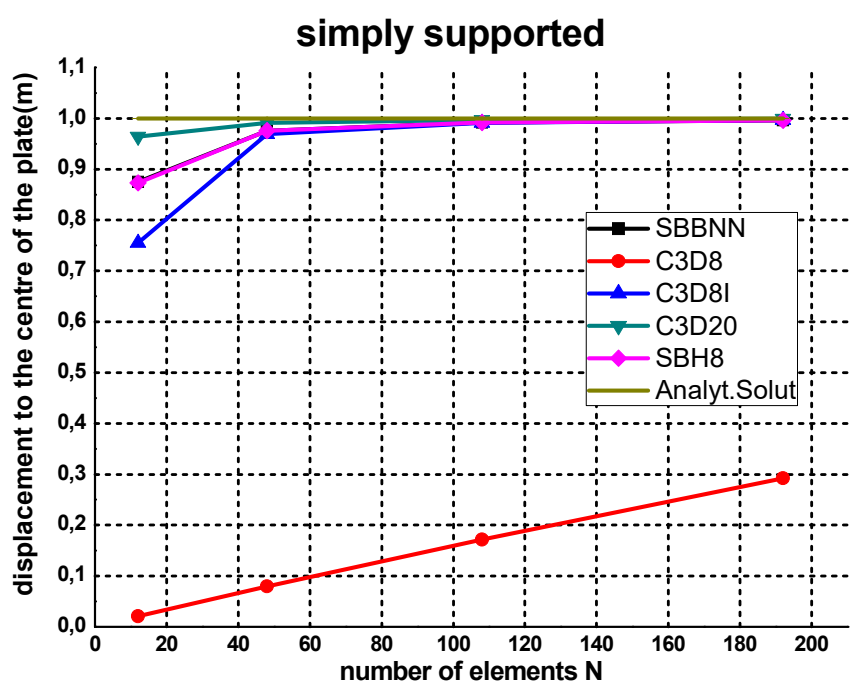

Fig. 7. Transverse displacement normalized to the center of the plate (simply supported).

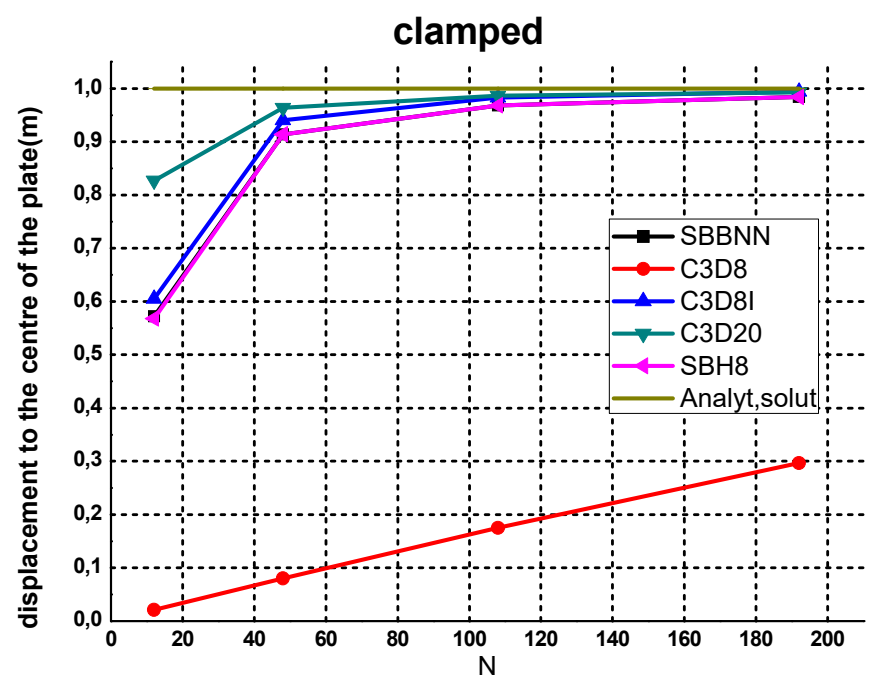

Fig. 8. Transverse displacement normalized to the center of the plate (clamped). 


\subsubsection{Transverse vibrations of a simply supported thin rectangular plate}

In this example, we study the transverse free vibrations of a simply supported thin rectangular plate. Fig. 9 shows the geometry and material characteristic of the plate which is modeled with a regular mesh. The analytical expressions of the transverse frequencies are given by:

$$
\mathrm{f}_{\mathrm{mn}}=\frac{\pi}{2}\left(\frac{\mathrm{m}^{2}}{\mathrm{~L}^{2}}+\frac{\mathrm{n}^{2}}{\mathrm{l}^{2}}\right) \sqrt{\frac{\mathrm{D}}{\rho h}}
$$

where $\mathrm{D}$ is the flexural rigidity of the plate defined as $D=\frac{E h^{3}}{12\left(1-v^{2}\right)}$.

Table 2 summarizes the obtained results.

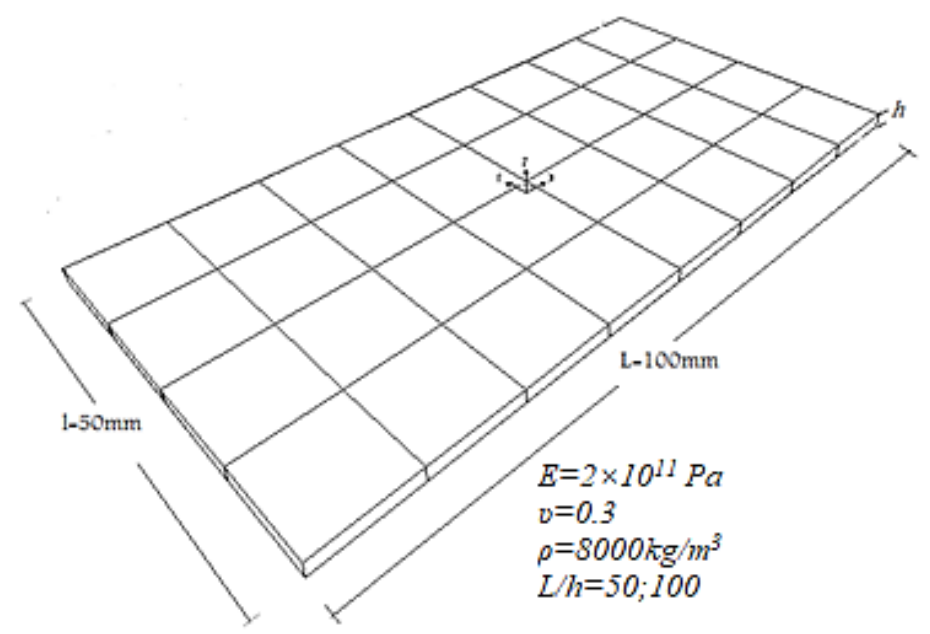

Fig. 9. The simply supported thin rectangular plate modeled with $8 \times 4 \times 1$ hexahedral elements.
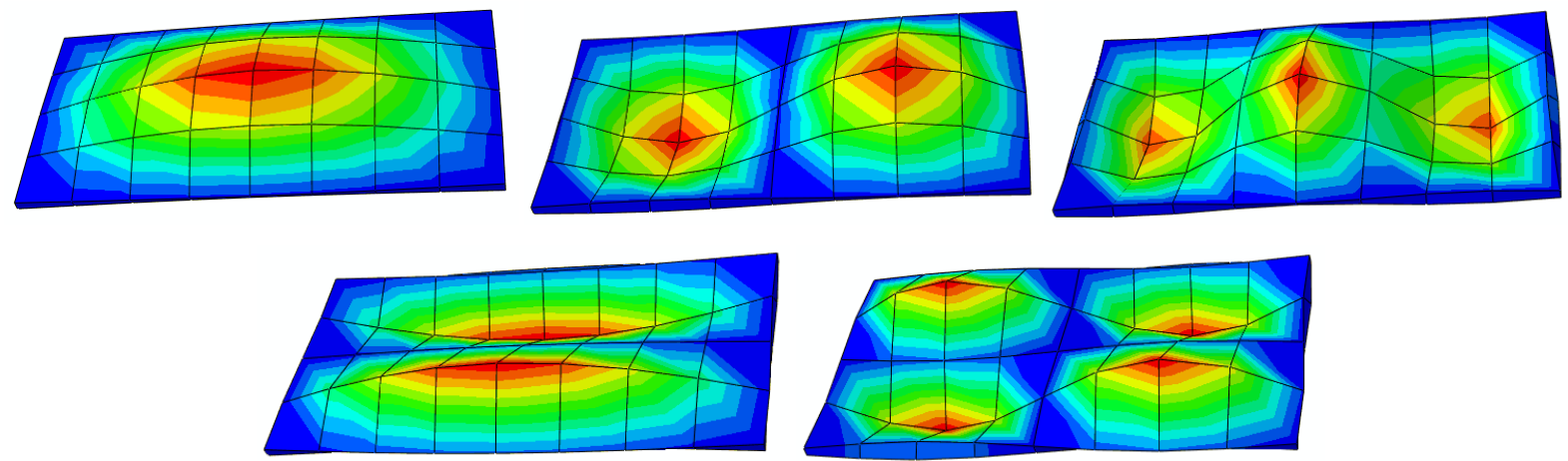

Fig. 10. The first five natural modes of rectangular plate. 
Table 2. The first five transverse natural frequencies.

$\begin{array}{lllllll}\text { C3D8 } & \text { C3D8I } & \text { C3D20 } & \text { SBBNN } & \text { SFR8 } & \text { SBH8 } & \text { Analyt.Solut. }\end{array}$

\begin{tabular}{llllllll}
\hline L/h=50 & & & & & & & \\
$\mathbf{f 1 1}$ & 72.821 & 25.149 & 23.961 & 25.062 & 26.447 & $\mathbf{2 6 . 5 9 0}$ & $\mathbf{2 3 . 7 6 7}$ \\
$\mathbf{f 2 1}$ & 96.968 & 42.270 & 38.183 & 41.026 & 41.856 & $\mathbf{4 3 . 5 6 5}$ & $\mathbf{3 8 . 0 2 7}$ \\
$\mathbf{f 3 1}$ & 165.57 & 71.879 & 63.087 & 70.536 & 69.172 & $\mathbf{7 5 . 0 7 6}$ & $\mathbf{6 1 . 7 9 4}$ \\
$\mathbf{f 1 2}$ & 277.57 & 93.762 & 86.211 & 93.949 & 96.68 & $\mathbf{1 0 0 . 2 0}$ & $\mathbf{8 0 . 8 0 8}$ \\
$\mathbf{f 2 2}$ & 273.66 & 117.73 & 100.1 & 115.94 & 110.34 & $\mathbf{1 2 4 . 0 7}$ & $\mathbf{9 5 . 0 6 8}$ \\
& & & & & & & \\
$\mathbf{L / h}=\mathbf{1 0 0}$ & & & & & & & \\
$\mathbf{f 1 1}$ & 71.737 & 14.835 & 12.096 & 12.703 & 13.296 & $\mathbf{1 3 . 4 8 1}$ & $\mathbf{1 1 . 8 8 3}$ \\
$\mathbf{f 2 1}$ & 95.073 & 28.774 & 19.437 & 21.211 & 21.136 & $\mathbf{2 2 . 5 3 7}$ & $\mathbf{1 9 . 0 1 3}$ \\
$\mathbf{f 3 1}$ & 163.32 & 52.003 & 32.63 & 38.967 & 35.129 & $\mathbf{4 1 . 5 3 5}$ & $\mathbf{3 0 . 8 9 7}$ \\
$\mathbf{f 1 2}$ & 276.39 & 56.994 & 44.527 & 50.096 & 49.094 & $\mathbf{5 3 . 5 4 3}$ & $\mathbf{4 0 . 4 0 4}$ \\
$\mathbf{f 2 2}$ & 271.94 & 88.053 & 52.889 & 67.377 & 56.909 & $\mathbf{7 2 . 3 7 0}$ & $\mathbf{4 7 . 5 3 4}$ \\
\hline
\end{tabular}

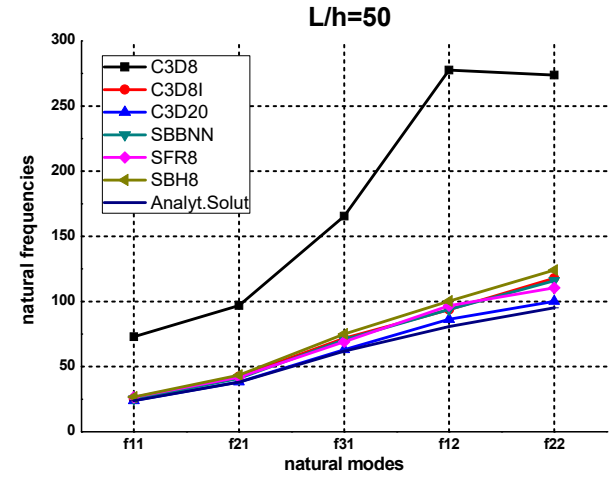

Fig. 11. The first five transverse natural Fig. 12. The first five transverse natural frequencies $(\mathrm{L} / \mathrm{h}=50)$

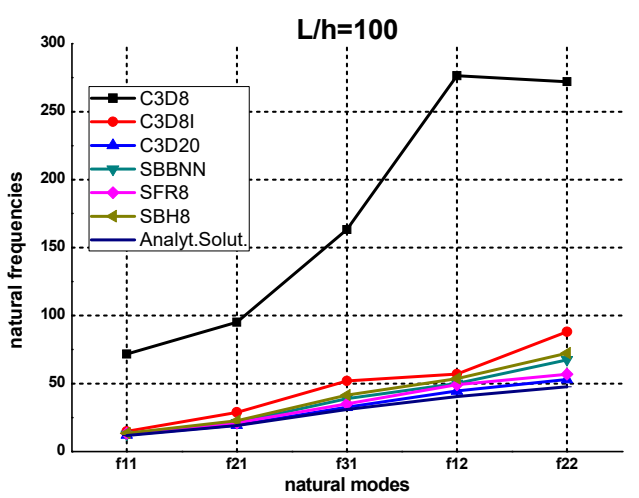

frequencies $(\mathrm{L} / \mathrm{h}=100)$

Figs. 10 to 12 present the first five mode shapes and natural frequencies of the investigated and analyzed plate. For the ratio $\mathrm{L} / \mathrm{h}=50$, it can be said that the results given by the SBH8 are almost the same as those of the SFR8 and C3D8I, whose characteristics are considered superior (d.o.f andincompatiblemodes) what will distinguish the present element. The SBH8 is very superior to the C3D8 element which has the same number of nodes. Relatively, the SBH8 shows good results. For the ratio $\mathrm{L} / \mathrm{h}=100$, the $\mathrm{SBH} 8$ proves that it is less sensitive to numerical locking and even surpasses the C3D8I for the five modes.

\subsubsection{Transverse vibrations of a thick square plate}

In this part, transverse free vibrations of a thick square plate shown in Fig. 13 are studied. Two configurations are considered: first, the plate with all sides clamped (C-C-C-C) and second, the plate is 
simply supported at two sides and clamped on one side, and free at the last side(C-S-S-F). Table 3 and Figs. 14 to 16 show the mode shapes and natural frequencies of the first four modes for the investigated example.

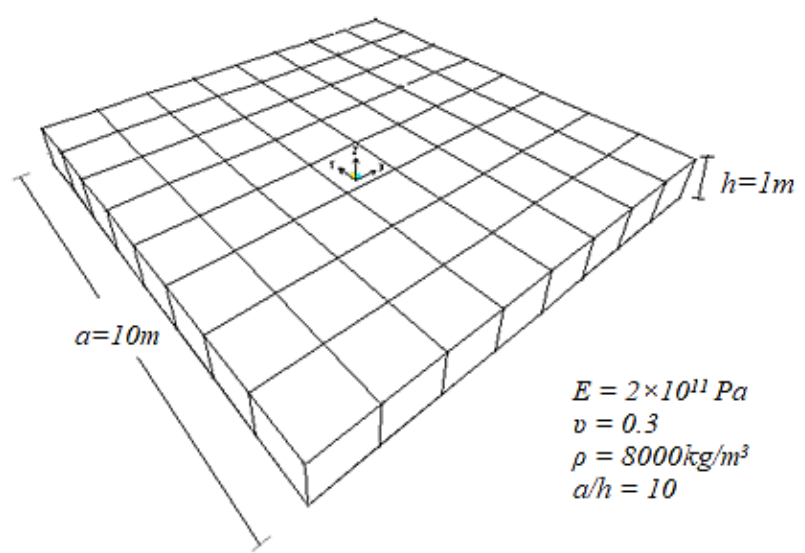

Fig. 13. The thick square plate modeled with $8 \times 8 \times 1$ hexahedral elements.
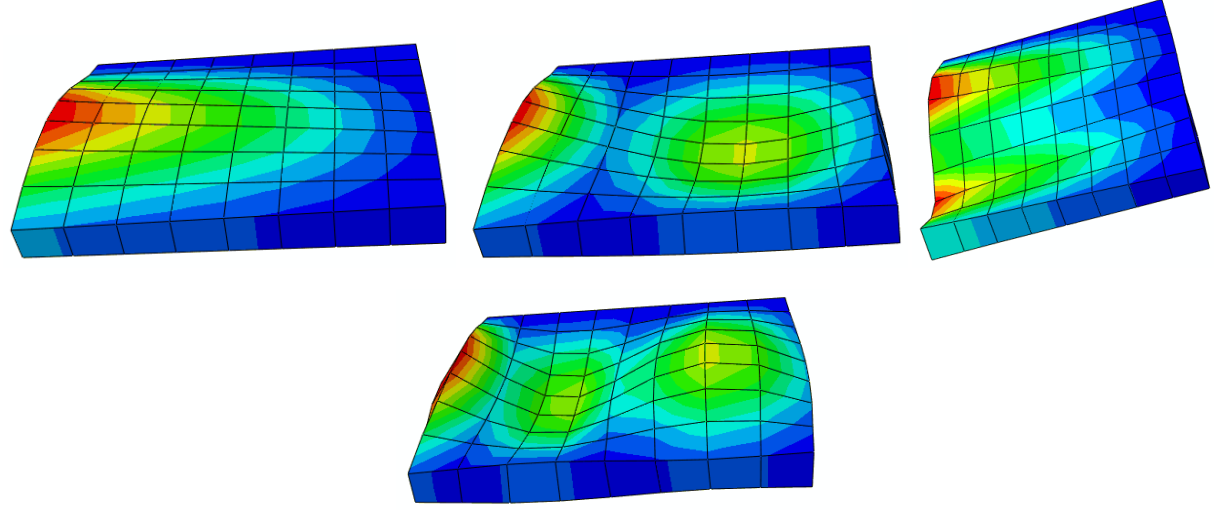

Fig. 14. The first four natural modes of thick square plate (CSSF).

Table 3. The first four transverse natural frequencies

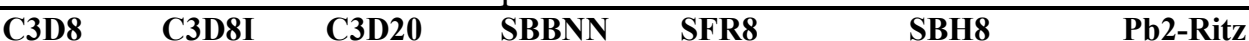

\begin{tabular}{llllllll}
$\mathbf{C C C C}$ & & & & & & & \\
$\mathbf{f 1 1}$ & 75.385 & 78.636 & 81.431 & 82.46 & 88.894 & $\mathbf{8 7 . 1 8 7}$ & $\mathbf{7 8 . 3 2 2}$ \\
$\mathbf{f 1 2 = f 2 1}$ & 145.25 & 150.11 & 156.46 & 157.87 & 172.77 & $\mathbf{1 6 6 . 2 7}$ & $\mathbf{1 4 9 . 3 9 6}$ \\
$\mathbf{f 2 2}$ & 187.73 & 199.97 & 219.53 & 220.76 & 241.53 & $\mathbf{2 3 1 . 6 4}$ & $\mathbf{2 0 9 . 3 8 4}$ \\
\hline CSSF & & & & & & & \\
\hline f11 & 38.095 & 38.539 & 38.933 & 39.266 & 41.650 & $\mathbf{4 1 . 5 2 7}$ & $\mathbf{3 8 . 4 9 1}$ \\
$\mathbf{f 1 2}$ & 61.311 & 65.884 & 69.098 & 68.847 & 74.282 & $\mathbf{7 2 . 4 6 3}$ & $\mathbf{6 9 . 3 1 7}$ \\
\hline $\mathbf{f 2 1}$ & 112.07 & 112.09 & 113.79 & 112.83 & 124.09 & $\mathbf{1 1 8 . 7 0}$ & $\mathbf{1 1 0 . 7 8 3}$ \\
$\mathbf{f 1 3}$ & 120.5 & 126.41 & 138.08 & 133.66 & 151.07 & $\mathbf{1 5 1 . 6 9}$ & $\mathbf{1 3 7 . 0 7 7}$ \\
\hline
\end{tabular}




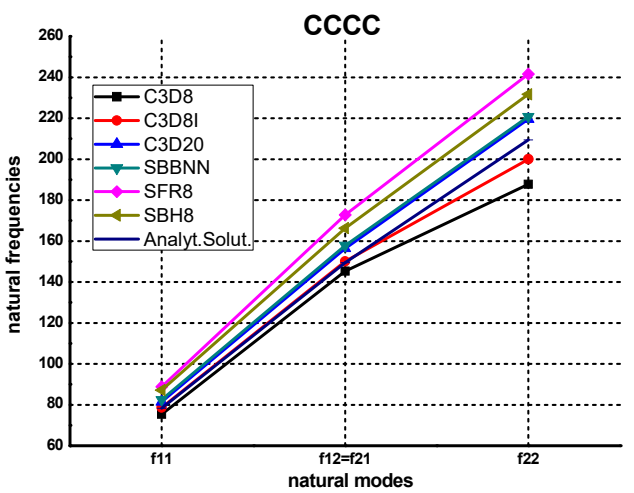

Fig. 15. The first four transverse natural frequencies $(\mathrm{CCCC})$

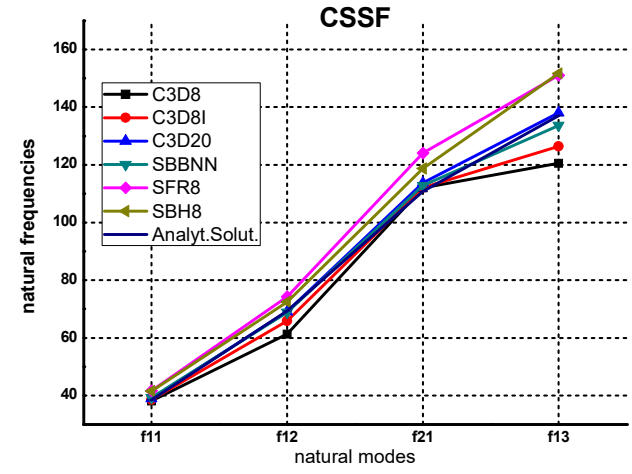

Fig. 16. The first four transverse natural frequencies (CSSF)

For the two cases (CCCC and CSSF), the results of the SBH8 are better than those of the SFR8, despite it possess a rotational d.o.f. It is seen from Figs. 15 and16, that the present element gives satisfactory results.

\section{Conclusions}

A study of the free vibration of thick and thin plates having various types of shapes and boundary conditions is presented to demonstrate the effectiveness of the strain based three dimensional elements. A hexahedral element, with only eight nodes, is implemented, for the first time, in the ABAQUS calculation code using the UEL subroutine. It has the advantage of being simple in form and uses the three essential degrees of freedom at each corner node. In the static analysis, the present element has a very good accuracy, convergence rate and superiority towards the reference solutions compared with other standard elements. This element gives very satisfactory performance, for the natural frequencies of thin plates, and compared with other available solutions, very acceptable results for thick plates. The efficiency of the three dimensional strain based element was demonstrated. The advantages to use this approach are now evident.

\section{Acknowledgements}

The authors wish to acknowledge kind supports provided by university of Batna 2 .

\section{References}

Abderrahmani, S., Maalem T., \& Hamadi D. (2018) The Transverse Shear Effect of a New Plate Bending Finite Element Based on the Strain Approach. International Journal of Engineering Research in Africa, 35, 1-10.

Ahmad S., Irons B.M., \& Zienkiewicz O.C. (1970) Analysis of thick and thin shell structures by curved elements, IJNME, 2, 419-451

Andelfinger, U., \& Ramm, E. (1993).EAS-elements for two-dimensional, three-dimensional, plate and shell structures and their equivalence to HR-elements. International Journal for Numerical Methods in Engineering, 36, 1311-1337.

Areias, P. M. A., César de Sá, J. M. A., António, C. A. C., \&Fernandes, A. A. (2003). Analysis of 3D problems using a new enhanced strain hexahedral element. International Journal for Numerical Methods in Engineering, 58(11), 1637-1682.

Ayad, R., Zouari, W., Meftah, K., Ben Zineb, T., \& Benjeddou, A. (2013).Enrichment of linear hexahedral finite elements using rotations of a virtual space fiber. International Journal for Numerical Methods in Engineering, 95(1), 46-70. 
Belarbi, M. T., \& Charif, A. (1999).Développement d'un nouvel élément hexaédrique simple basé sur le modèle en déformation pour l'étude des plaques minces et épaisses. Revue Européenne des Eléments, 8(2), 135-157.

Belarbi, M. T., \& Maalem, T. (2005). On improved rectangular finite element for plane linear elasticity analysis. Revue Européenne des Eléments, 14(8), 985-997.

Belounar, L., \& Guenfoud, M. (2005).A new rectangular finite element based on the strain approach for plate bending. Thin-Walled Structures, 43(1), 47-63.

Belounar, L., \& Guerraiche, K. (2014). A new strain based brick element for plate bending. Alexandria Engineering Journal, 53, 95-105

Belounar, A., Benmebarek, S., \& Belounar, L. (2020). Strain based triangular finite element for plate bending analysis. Mechanics of Advanced Materials and Structures, 27(8), 620-632.

doi:10.1080/15376494.2018.1488310

De Sousa, R. J. A., Jorge, R. M. N., Valente, R. A. F., \& de Sá, J. M. A. C. (2003). A new volumetric and shear locking-free 3D enhanced strain element. Engineering Computations, 20, 896-925.

Djoudi, M. S., \& Bahai, H. (2004a). A cylindrical strain-based shell element for vibration analysis of shell structures. Finite Elements in Analysis and Design, 40(13-14), 1947-1961.

Djoudi, M. S., \& Bahai, H. (2004b). Strain based finite element for the vibration of cylindrical panels with openings. Thin-Walled Structures, 42(4), 575-588.

Guerraiche, K., Belounar, L., \& Bouzidi, L. (2018). A new eight nodes brick finite element based on the strain approach. Journal of Solid Mechanics, 10(1), 186-199.

Liew, K., Xiang, Y., \& Kitipornchai, S. (1993). Transverse vibration of thick rectangular platesI.comprehensive sets of boundary conditions. Computers \& Structures, 49(1), 1-29.

Maalem, T. (2014). Performances of the 3d strain based finite elements. Courrier du Savoir, 11, 27.

Messai, A., Belounar, L., \& Merzouki, T. (2018). Static and free vibration of plates with a strain based brick element. European Journal of Computational Mechanics, 1-21.

DOI: 10.1080/17797179.2018.1560845

Piltner, R., \& Taylor, R. L. (1995). A quadrilateral mixed finite element with two enhanced strain modes. International Journal for Numerical Methods in Engineering, 38, 1783-1808.

Rebiai, C., \& Belounar, L. (2013). A new strain based rectangular finite element with drilling rotation for linear and non linear analysis. Archives of Civil and Mechanical Engineering, 13, 72-81.

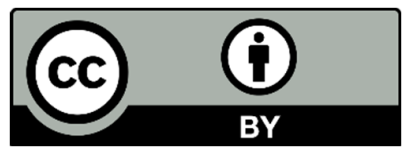

(C) 2021 by the authors; licensee Growing Science, Canada. This is an open access article distributed under the terms and conditions of the Creative Commons Attribution (CC-BY) license (http://creativecommons.org/licenses/by/4.0/). 